\title{
A floresta estacional decidual no Brasil: distribuição geográfica e influência dos aspectos pedogeomorfológicos na vegetação
}

\author{
The Deciduous Seasonal Forest in Brazil: Geographic Distribution and Influence of the pedogeomorphologic aspects on \\ Vegetation
}

\section{Thamyres Sabrina Gonçalves}

Geógrafa, Mestranda em Ciência Florestal na Universidade Federal dos Vales do Jequitinhonha e Mucuri.

\begin{abstract}
Resumo
A maior parte dos estudos realizados em ambientes florestais, no Brasil, foi executada em ambientes úmidos, enquanto as florestas tropicais secas são quase sempre negligenciadas em termos de pesquisas, o que, consequentemente, influencia na conservação desses ecossistemas. Desse modo, gerar conhecimentos acerca dessa fitofisionomia é muito importante para a elaboração de estratégias eficazes e efetivas de conservação das florestas estacionais deciduais e de garantia dos direitos sociais das comunidades que vivem dos recursos dessas florestas. Nesse contexto, o objetivo do presente estudo é fazer uma revisão da literatura acerca dos processos de correlação entre as características pedológicas e a estrutura da vegetação nas florestas estacionais deciduais, ao longo da escala espacial em que se distribuem essas formações. Por ser um ecossistema amplamente marcado pelo estresse hídrico e climático, a interação solo-planta tende a ser mais forte nas florestas estacionais deciduais do que em outros tipos de floresta tropical, como as florestas úmidas, desse modo, a não geração, divulgação e propagação de conhecimento sobre a ecologia desse ecossistema implica na utilização de estratégias de conservação e manejo, elaboradas a partir de estudos realizados em outras formações, que podem não ser aplicáveis às Matas Secas em sua ampla diversidade de hábitats e condições estruturais, geográficas e pedogeomorfológicas. Assim, é necessário avançar na realização de pesquisas que contemplem a interação entre os diversos componentes da paisagem que abriga as florestas estacionais deciduais.
\end{abstract}

Palavras-chaves: Conservação. Interação solo-vegetação. Singularidades florísticas

\begin{abstract}
Most studies in forest environments in Brazil, were executed in rain tropical forests. The tropical dry forests are often neglected in terms of research which consequently influences the conservation of these ecosystems. Generating knowledge about this vegetation type is very important for the development of efficient and effective strategies for conservation of deciduous forests and guarantee of social rights of communities on resources of these forests. In this context, the aim of this study is to review the literature on the correlation processes between characteristics pedogeomorphologic and structure of vegetation in deciduous forests along the spatial scale at which these formations are distributed. Being a widely ecosystem marked by climatic stress and hidric interaction a soil-plant and landscape tends to be strongest in deciduous forests than in other types of tropical rainforests. So it is necessary to move forward in conducting research that address the interaction between the various components of the landscape that houses the deciduous forests.
\end{abstract}

Keywords: Conservation. Interaction soil-landscape. Hetegeneous floristic 


\section{INTRODUÇÃO}

Conhecer a flora de uma região e os padrões que determinam a estrutura da vegetação é de suma importância para que se possa avançar na elaboração de planos de conservação que contemplem a tão necessária multidisciplinaridade, já que esses padrões envolvem diferentes variáveis ambientais e edáficas (CAMARGOS et al., 2008). São diversos os fatores que influenciam na estruturação de uma comunidade florestal (SANTOS et al., 2012), dentre estes, as interações bióticas e abióticas possuem grande relevância na ecologia de florestas estacionais deciduais (FED's), sobretudo aquelas que ocorrem nas áreas de afloramentos rochosos (ESPÍRITO-SANTO et al., 2008). Conhecer a importância dessas interações é necessário para o entendimento da dinâmica ecológica das Matas Secas, como são chamadas regionalmente essas florestas. De acordo com Maragon et al. (2003), o conhecimento e o entendimento das complexas relações que envolvem as florestas tropicais devem iniciar-se pelo levantamento florístico. Levantamentos florísticos são fundamentais para o desenvolvimento de estudos ecológicos e evolutivos (BÜNGER, 2011). O conhecimento da flora tem auxiliado no entendimento dos padrões fitogeográficos das espécies e da organização espacial das comunidades florestais (BÜNGER, 2011; GONZAGA, 2011; SILVA, 2011).

As Matas Secas são pouco estudadas de um modo geral, sobretudo se comparadas às florestas de ambientes úmidos (ESPÍRITO-SANTO, 2006). Apenas 14\% dos estudos realizados em florestas tropicais foram feitos em ambientes secos, enquanto $86 \%$ foram realizados em regiões úmidas (SANCHEZ-AZOFEIFA et al., 2005). Desse modo, existe uma carência de informações acerca dessas florestas, principalmente no que se refere aos processos pedogeomorfológicos. Assim, conhecer as espécies que ocorrem na vegetação, tanto no estrato arbóreo como na regeneração natural, e as características dos solos sobre o qual se desenvolvem em muito pode ajudar na conservação das FED's no Brasil.

Aumentar o conhecimento acerca da biodiversidade e dos processos de regeneração natural nas florestas estacionais decíduas conduz ao aperfeiçoamento das estratégias de conservação desses ambientes. Portanto, esse trabalho faz uma revisão acerca das influencias mútuas e dinâmicas entre solo e vegetação nas florestas estacionais deciduais brasileiras. Vale ressaltar que são praticamente inexistentes estudos, mesmo que de revisão bibliográfica, com vistas a gerar conhecimentos acerca dos processos de correlação espécie-ambiente em florestas estacionais deciduais ao longo de gradientes pedogeomorfológicos, e que, por este motivo, é praticamente desconhecida a influência do ambiente abiótico, topográfico, geológico, geomorfológico e pedológico na ecologia das espécies que compõem a FED.

\section{DESENVOLVIMENTO}

Conhecidas como Florestas Estacionais Deciduais, no campo da pesquisa, e como Matas Secas, na nomenclatura popular, estas mesmas formações são definidas na escala global como Florestas Tropicais Secas (FTS) (ESPÍRITO-SANTO et al., 2006) e representam uma parcela importante da biota brasileira. A definição destas florestas é bastante ampla, referem-se, de um modo geral, às formações arbóreas que ocorrem em regiões com duas estações bem definidas, uma seca e outra chuvosa (MURPHY \& LUGO, 1986; NASCIMENTO et al., 2004).

A vegetação das FED's é tipicamente decídua, com perda das folhas superior a 50\% na estação seca do ano, sabendo-se que os índices de deciduidade da floresta podem ser variáveis (ESPÍRITOSANTO et al., 2006). Avaliando sobre a cobertura do dossel em fragmentos de FED na região central do Brasil, Nascimento et al. (2007) constataram que mais de $90 \%$ das árvores perdem as folhas durante a estação seca do ano. O dossel pode atingir de 10 a 40m de altura, a depender da profundidade do solo, com árvores emergentes chegando a 30m (OLIVEIRA-FILHO, 2006; ESPÍRITO-SANTO et al., 2006). A temperatura média anual é de $25^{\circ} \mathrm{C}$ e a precipitação anual média varia entre 700 e $2000 \mathrm{~mm}$, com pelo menos três meses secos por ano (SÁNCHEZ-AZOFEIFA et al., 2005), com base na média global para as FTS, todavia variam muito em toda a região neotropical, já que esta apresenta discrepâncias quantitativas no regime pluviométrico (ESPÍRITO-SANTO et al., 2008). A distribuição sazonal da precipitação nas FED's é tão importante quanto o volume total das chuvas (AYOADE, 2007), podendo influenciar nos processos de dispersão, germinação e estabelecimento de espécies (LIMA et al., 2008; LARCHER, 2000), o que, consequentemente, afeta a composição florística e a estrutura da vegetação, 
além das características morfológicas, físico-químicas e estruturais do solo.

A influência da precipitação no solo de ambientes florestais depende da altura e da estrutura do dossel. No caso das FEDs, também há uma influência muito grande da topografia, pois, a depender do relevo regional, as Matas Secas podem ocorrer em regiões planas, sobre solos mais profundos, como no norte de Minas Gerais, ou em terrenos íngremes, com grande quantidade de blocos ou paredões de rochas afloradas, como nas partes mais baixas da Serra do Espinhaço Meridional, em solos mais rasos e dossel descontínuo, o que torna o solo mais suscetível a perda de nutrientes por lixiviação e aumento do $\mathrm{pH}$.

Além disso, a quantidade de água disponível ás plantas depende diretamente das características que constituem o solo, como textura e estrutura (SANTOS; CARLESSO, 2008), e a interação solo-planta tende a ser mais intensa em ambientes com déficit hídrico, o que reforça a compreensão de que os aspectos pedológicos são definidores na composição das espécies que compõem a FED, de modo que a correlação entre os atributos do solo e a regeneração natural da floresta pode inferir na estrutura da vegetação.

Em relação aos aspectos pedológicos, a história da humanidade, a partir da ciência do solo, mostra que o desenvolvimento das sociedades se relaciona ao conhecimento do homem acerca dos diferentes tipos de solo, de modo que a fixação humana e o adensamento populacional se concentram em áreas de solos considerados mais ricos e férteis (LEPSCH, 2010). De encontro a essa concepção, as áreas de FED's constituem-se, geralmente, em zonas de intensa utilização humana, de modo que as pressões antrópicas devastaram imensas áreas de vegetação nativa de FED's (DRUMMOND et al., 2005). Portanto, questões relacionadas aos processos de uso e ocupação do solo são a mais forte pressão antrópica sobre os ambientes de floresta estacional decidual no Brasil. Apesar disso, são poucos os trabalhos com mapeamento e uso de sistemas de informação geográfica nesses tipos de ambientes.

A formação dessas florestas secas ocorreu de forma extensa e contínua, presumivelmente nos períodos mais secos e frios do pleistoceno (PENNINGTON et al. 2000), desse modo, a origem das Matas Secas em áreas de transição entre o cerrado e a caatinga, no Brasil, está relacionada ao processo de expansão e retração de florestas durante o período quaternário (SILVA, 2010; RODRIGUES, 2009; AB' SABER, 1977, 2003). Apesar do processo de formação ter acontecido continuamente em termos de expansão geográfica, as FED's tendem a ocorrer em manchas disjuntas na região neotropical (PENNINGTON et al., 2000), suas bordas são definidas, principalmente, pela variação nas características do solo (NASCIMENTO et al., 2004; SALIS et al., 2004). De acordo com Silva (2011), os fatores topografia e solo são os principais elementos de influência na vegetação em áreas ecotonais, determinando, por exemplo, a dominância de algumas espécies, além da quantidade de estratos e a densidade de árvores dentro da floresta, indicando que a definição do estágio sucessional depende desses dois fatores.

Comparando as diferenças estruturais e edáficas entre uma floresta estacional decídua e uma semidecídua, na região oeste de Minas Gerais, Kilca et al (2009) verificaram que as espécies arbóreas dominantes em FED's são especializadas a solos muitos férteis. No mundo inteiro, as FED's estão distribuídas nas Américas do sul e central. África. Ásia e Oceania (MURPHY: LUGO, 1986).

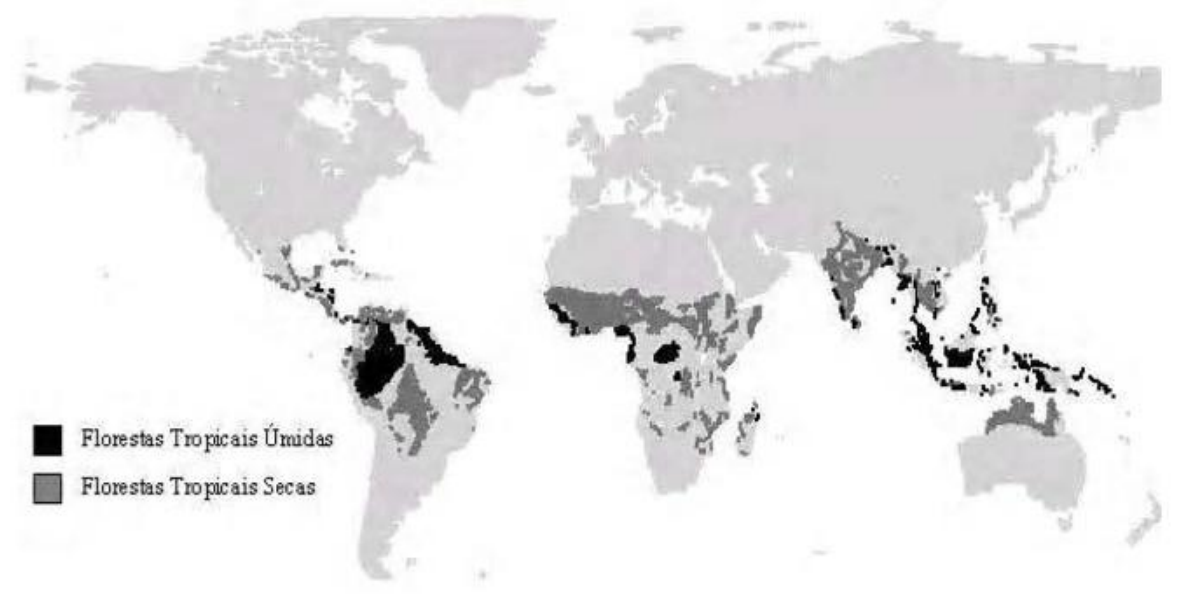

Figura1 - Mapa da Distribuição geográfica das Matas Secas na escala global. Fonte: Espírito-Santo (et al., 2006). 
No Brasil, são encontradas, principalmente, na região central e nordeste do país (SALIS et al. 2004; TABARELLI, 2006; SEVILHA et al, 2004) e cobrem 6, 02\% do território brasileiro (EMBRAPA, 2011; ESPÍRITO-SANTO et al., 2008). Apesar de estarem geograficamente concentradas nas regiões nordeste e sudeste do Brasil, as florestas sazonais ocorrem, mesmo que em pequenos fragmentos, em todos os biomas brasileiros.

Uma das grandes dificuldades na busca de padrões de manejo adequado para esses ambientes se deve às grandes variações na estrutura da vegetação em todo o Brasil, pois não há como se definir um padrão de práticas adequadas, tanto de manejo quanto de gestão, que funcione satisfatoriamente para todos os planos de manejo e gestão das áreas protegidas no país. Na verdade, é preciso conhecer melhor como o ecossistema funciona em cada região para definir a forma correta de manejar essas florestas, incluindo as comunidades que vivem em cada lugar e as interações entre os diferentes elementos bióticos e abióticos da paisagem.

A fitogeografia brasileira tem conduzido muitas discussões acerca da classificação da vegetação do Brasil (FERNANDES, 2008; RIZZINI, 1997; IBGE, 1992). De acordo com Júnior (2012), tal fato se deve ao surgimento de novas metodologias de classificação e ao acúmulo de conhecimentos. A floresta atlântica, também conhecida como mata atlântica, representa a região florística que mais tem sido alvo de divergências quanto a sua classificação (JÚNIOR, 2012; ZHOURI et al., 2008; ROCHA; BARBOSA, 2012; RIBEIRO et a1., 2009; ESPÍRITO-SANTO, 2010; TROPI-DRY, 2010). Com base na legislação ambiental, regulamentada pelo decreto-lei no 750, de 10 de fevereiro de 1993, e pela lei $\mathrm{n}^{\mathrm{o}} 11.428$, de 22 de dezembro de 2006, conhecida como a lei da mata atlântica, considera-se a floresta estacional decidual como formação florestal integrante do bioma mata atlântica.

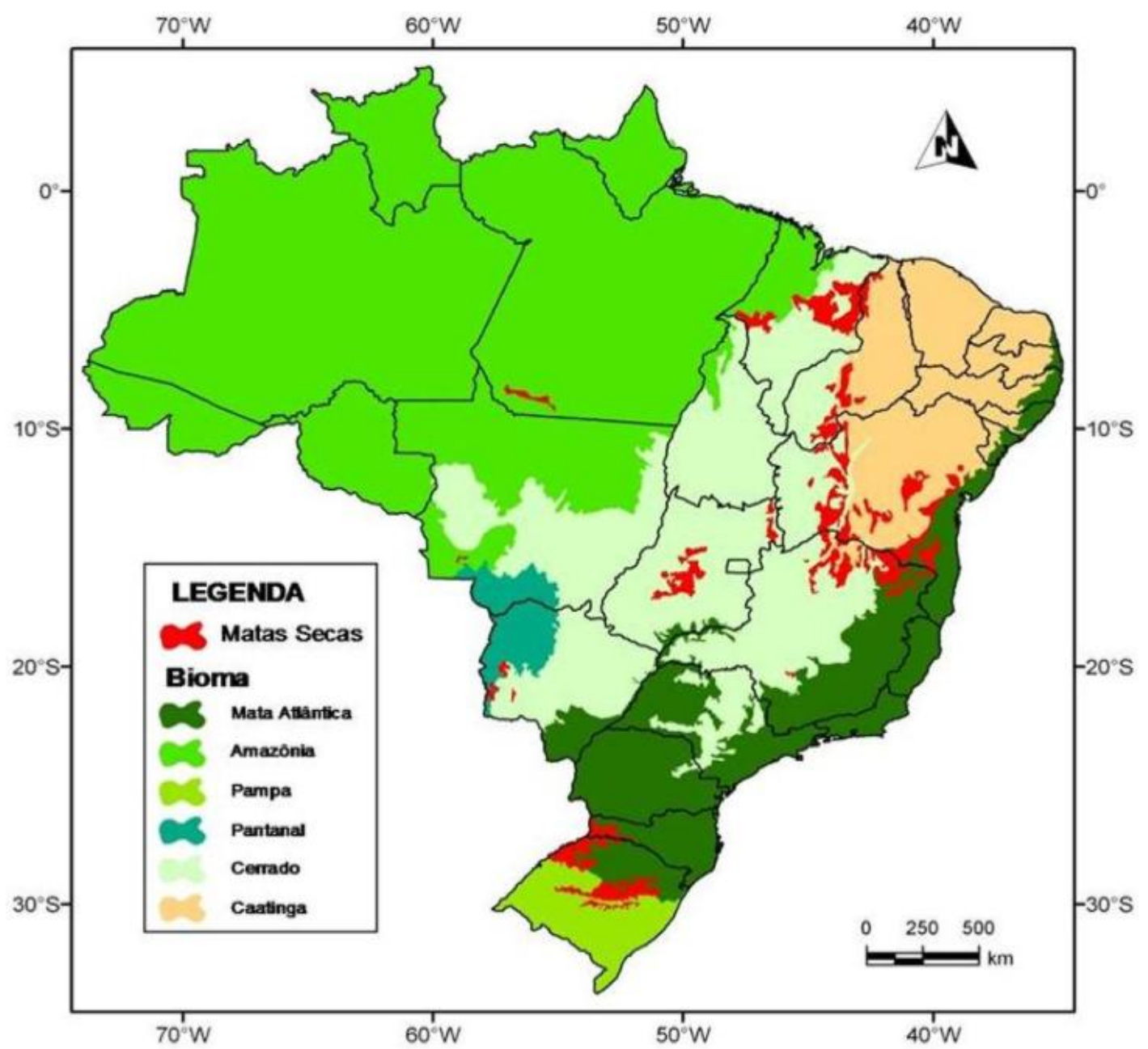

Figura 2 - Mapa da Distribuição das Matas Secas no território brasileiro Fonte: ESPÍRITO-SANTO et al., 2008 
A floresta estacional decidual sobre solos de origem calcária, onde ocorre a maior parte das formações florestais de Matas Secas (FEDs), é considerada de importância singular, pois apresenta flora e fisionomia própria, bem distinta de outras formações sobre outros tipos de solos. (PEDERSOLI; MARTINS, 1972; IVANUSKAS; RODRIGUES, 2000; KAMINO et al., 2008; RIZZINI, 1997). Os calcários são rochas sedimentares compostas, basicamente, por calcita $\left(\mathrm{CaCO}_{3}\right)(\mathrm{SAMPAIO}$; ALMEIDA, 2008). Devido à sua composição mineralógica, as calcitas são, geralmente, muito fraturadas em função da fácil dissolução da rocha, provocada pela água que, associada ás condições de temperatura e pressão no ambiente, propicia a abertura de fendas nas rochas (DUNBAR \& RODGERS, 1963; ROCHA, 2011), o que leva ao estabelecimento de espécies adaptadas a se desenvolverem sobre estas fendas, criando micro hábitats dentro das FED's (GONZAGA, 2011; RODRIGUES; RIBEIRO, 2009; FERREIRA, 2011). Alguns estudos mostram que as fendas das rochas podem influenciar no microclima, no que se refere à umidade relativa, já que as estratificações podem atuar na retenção de umidade (ATINGEM et al., 2011; PILÓ; AULER, 2009). Compreender a composição mineral dessas rochas é importante para o entendimento das características do solo que se desenvolve sobre essas áreas de afloramentos rochosos (DUNBAR; RODGERS, 1963), uma vez que os minerais componentes da rocha calcária podem influenciar a composição e, também, a estrutura e a profundidade do solo (SHINZATO, 1998), o que afetará a composição florística e a estrutura da vegetação (SKORUPA et al., 2012). A cobertura vegetal, por sua vez, também atua significativamente sobre as características do solo, através da deposição de matéria orgânica, auxiliando na formação e na manutenção da fertilidade dos solos (KÖNIG et al., 2002; CUNHA et al., 1993).

As FED's encontram-se distribuídas, em sua maior parte, dentro do bioma cerrado, existindo, também, fragmentos sobre o domínio da caatinga e em áreas de transição (PEDRALLI, 1997; SILVA, 2011). Assim, as fitofisionomias podem apresentar componentes da vegetação na qual estão inseridas, formando uma comunidade diferente em cada região (SCARIOT; SEVILHA, 2005). De acordo com Cavalcanti (2011), o potencial da diversidade biológica em áreas de FEDs se expande nas zonas de ecótonos. Nos últimos dois séculos, essas florestas foram reduzidas a pequenos fragmentos, geralmente com alto índice de perturbação, pois houve grande desmatamento desses ambientes para implantação de agricultura, silvicultura e pastagens (GERHARDT, 1994; WERNECK et al., 2000, IEF, 2008).

Mas, apesar de constituírem, atualmente, uma paisagem vastamente antropizada, apresentam alta riqueza de espécies (SCARIOT; SEVILHA, 2005; OLIVEIRA-FILHO, 2006) Além disso, alguns autores (SAMPAIO; ALMEIDA, 2008; DUNBAR; RODGERS, 1963) afirmam que a exploração econômica do calcário tem influenciado a degradação das FED's. O conhecimento sobre as florestas tropicais no mundo e, principalmente, nas Américas é concentrado nas florestas úmidas, como a Amazônia e a Mata Atlântica. Desse modo, estudos com vistas ao reconhecimento da biodiversidade em ambientes secos se fazem necessários ao direcionamento de ações de conservação (ESPÍRITOSANTO et al., 2006; BULLOCK, 1995; RODRIGUES et al., 2005; VALENTE, 2009; VIEIRA, 2006; GONÇALVES; VELOSO, 2013).

\section{CONSIDERAÇÕES FINAIS}

A pesquisa em biodiversidade, no Brasil, além de muitas lacunas no conhecimento, possui muita falta de integração entre as diferentes áreas das ciências ambientais. Conservar florestas depende de conservar solos e serras. Definir áreas prioritárias para a criação de unidades de conservação, por sua vez, demanda conhecimento sobre o ecossistema e seus processos e serviços, para isso é necessário fazer pesquisas integradas. E, por fim, tornar essas áreas protegidas efetivamente conservadas depende de um diálogo social entre comunidades e órgãos gestores. Nos últimos dez anos, notam-se importantes avanços no conhecimento sobre as florestas estacionais deciduais no Brasil, mas pouco disso tem se convertido, de fato, em estratégias de conservação e menos ainda de manejo das Matas Secas. Espera-se que o conhecimento gerado até aqui possa servir de base para melhor compreensão desses importantes resquícios da floresta atlântica enclavados pelos cerrados e caatingas do país. 


\section{AGRADECIMENTOS}

A todos do Laboratório de Ecologia e Propagação Vegetal pelo apoio com a realização da pesquisa. À FAPEMIG, ao CNPq e à CAPES. Às redes de pesquisas Tropy-Dry e Matas Secas pela coordenação do projeto de pesquisa "Biodiversidade e Regeneração Natural em Florestas Tropicais Secas no Nordeste e Sudeste do Brasil". Ao Sistema Brasileiro de Pesquisa em Biodiversidade. Ao IBAMA pelo apoio logístico no Parque Nacional da Serra do Cipó e Area de Proteção Ambiental Morro da Pedreira. Ao professor Dr. Expedito José Ferreira pelas contribuições ao texto.

\section{REFERÊNCIAS:}

ATINGEM, N. V.; SCHERER, B. S.; VARÃO, A. M. Estudos espeleológicos das cavidades naturais da UHE Estreito / MT- TO: prospecção e documentação básica. In: Anais do $31^{\circ}$ Congresso Brasileiro de Espeleologia. Ponta Grossa, Paraná, 2011.

ALMEIDA-ABREU, P. A.; RENGER, F. E. Serra do Espinhaço meridional: um orógeno de colisão do mesoproterozóico. Revista Brasileira de Geociências, vol.32, n.1, pg.1-14, 2002.

BRASIL. Decreto $\mathbf{n}^{\circ} 750$ de 10 de fevereiro de 2003 que dispõe sobre o corte, a exploração e a supressão de vegetação primária ou nos estágios avançado e médio de regeneração da mata atlântica, e dá outras providencias. Disponível em: http://www.ibama.gov.br/flora/decretos/750 93.pdf Acesso em Jan. 2012.

BRASIL. Lei ${ }^{\circ} 11.428$ de 22 de dezembro de 2006 que dispõe sobre a utilização e proteção da vegetação nativa do bioma mata atlântica, e dá outras providencias. Disponível em: http://www.planalto.gov.br/ccivil 03/ ato2004-2006/2006/lei/111428.htm Acesso em Jan de 2012.

BULLOCK, S. H.; MOONEY, H. A.; MEDINA, E. Seasonally dry tropical forests. Cambridge University Press, 1995.

BÜNGER, M. O. Myrtacea na Cadeia do Espinhaço: a flora do Parque Estadual do Itocolomi (Ouro Preto/ Mariana) e uma análise das relações florísticas e da influência das variáveis geoclimáticas na distribuição das espécies. Dissertação de Mestrado, Instituto de Ciências Biológicas da Universidade Federal de Minas Gerais, 2011.

CAMARGOS, V. L.; SILVA, A. F.; NETO, J. A. A. M.; MARTINS, S. V. Influência de fatores edáficos sobre variações florísticas na Floresta Estacional Semidecídua no entorno da Lagoa Carioca, Parque Estadual do Rio Doce, MG, Brasil. Revista Acta Botânica Bras. V. 22, n.1, pg. 75 - 84, 2008.

CAMPANILI, M.; PROCHNOW, M. (Orgs.) Mata Atlântica - uma rede pela floresta. Rede de Ongs da Mata Atlântica, Brasília, 2006.

CAVALCANTI, L. F.; LIMA, M. F.; MEDEIROS, R. C. S.; MEGUERDITCHIAN, I. Plano de ação nacional para conservação do patrimônio espeleológico nas áreas cársticas da bacia do rio São Francisco. Instituto Chico Mendes de Conservação da Biodiversidade, 2011.

CUNHA, G. C.; GRENDENE, L.A.; DURLO, M. A.; BRESSAN, D. A. Dinâmica nutricional em floresta estacional decidual com ênfase aos minerais provenientes da deposição da serrapilheira. Revista Ciência Florestal, vol.3, n.1, p.35-64, 1993.

DRUMMOND G. M., MARTINS C. S., MACHADO A. B. M., SEBAIO F. A., ANTONINI Y. Biodiversidade em Minas Gerais. Fundação Biodiversitas. Belo Horizonte. 2005.

DRUMMOND G. M., MARTINS C. S., MACHADO A. B. M., SEBAIO F. A., ANTONINI Y. Biodiversidade em Minas Gerais: um atlas para sua conservação. $2^{a}$ Ed., Fundação Biodiversitas, Belo Horizonte, 2007. 
DUNBAR, C. O,; R, J. Princípios de estratigrafia. Compañia Editorial Continental, México: 1963.

EMBRAPA. EMPRESA BRASILEIRA DE PESQUISA AGROPECUÁRIA. Mapa da cobertura vegetal do Brasil. Disponível em: http://www.cobveget.cnpm.embrapa.br/ acesso em 01/11/2011.

ESPÍRITO-SANTO, M. M. Mata Seca Ameaçada. Revista Ecológico. Pg. 32-37, Janeiro de 2010. Disponível em: http://tropi-dry.eas.ualberta.ca/pdf/Papers/Rev EcoJan10 MataSeca Web.pdf Acesso em nov. 2012.

ESPÍRITO-SANTO, M. M.; FAGUNDES, M.; NUNES, Y. R. F.; FERNANDES, G. W.; AZOFEIFA, G. A. S. QUESADA, M. Bases para a conservação e uso sustentável das florestas estacionais deciduais brasileiras: a necessidade de estudos multidisciplinares. Revista Unimontes Científica, vol. 8, n. 1, 2006.

ESPÍRITO-SANTO, M. M.; FAGUNDES, M.; SEVILHA, A. C.; SCARIOT, A. O.; AZOFEIFA, G. A. S.; NORONHA, S. E.; FERNANDES, G. W. Florestas estacionais deciduais brasileiras: distribuição e estado de conservação. MG Biota, v.1, n.2, 2008.

FERNANDES, A. Fitogeografia brasileira. Multigraf, Fortaleza, 1998. 340p.

FERREIRA, R. L. Biologia subterrânea: conceitos gerais e aplicação na interpretação e análise de estudos de impacto ambiental. In: III Curso de espeleologia e licenciamento ambiental. Centro Nacional de Pesquisa e Conservação de Cavernas, ICMBIO, Brasília - DF, pg. 89-113, 2011.

GERHARDT, K. Seedling development of four tree species in secondary tropical dry forest in Guanacaste, Costa Rica. Comprehensive Summaries of Uppsala Dissertations. Facult os Science and Tecnology, 1994.

GIULIETTI, A. M.; PIRANI, J. R. \& HARLEY, R. M. Espinhaço Range Region, Eastern Brazil. In: Davis, S. D.; Heywood, V. H.; Herrera-MacBryde, O.; Villa-Lobos, J. \& Hamilton, A. C. (Ed.) Centres of Plant Diversity. The Americas. Vol. 3. World Wide Fund For Nature, Oxford. pp. 397-404. 1997.

GIULIETTI, A. M. et al. Flora da Serra do Cipó: caracterização e lista de espécies. Boletim de Botânica da Universidade de São Paulo, vol.9, pg.1-152, 1987.

GIULIETTI, A. M. \& PIRANI, J. R. Patterns of geographic distribution of some plant species from the Espinhaço Range, Minas Gerais and Bahia. Pp. 39-69. In: Vanzolini, P. F. \& Heyer, W.R. (Eds.). Proceedings of a workshop on neotropical distribution patterns. Rio de Janeiro, Academia Brasileira de Ciências. 1987.

GONÇALVES, T. S.; VELOSO, M. D. M. Demandas para pesquisa: correlação entre as características pedológicas e a vegetação em florestas estacionais deciduais. Anais do II Simpósio Mineiro de Ciência do Solo Fertilidade do solo: conhecimentos, aplicações, interfaces e desafios. Sociedade Brasileira de Ciências do Solo. Universidade Federal de Viçosa, 2013.

GONZAGA, A. P. D.; Padrões fitogeográficos de florestas estacionais deciduais na bacia do rio São Francisco: análise florístico-estrutural e suas relações com o ambiente. Tese de Doutorado em Ciências Florestais. PPGEFL, Brasília - DF, 2011.

IEF- INSTITUTO ESTADUAL DE FLORESTAS. Parque Estadual da Mata Seca: ecologia, ocupação humana do entorno e conservação. MG Biota: Boletim Técnico Científico da Diretoria de Biodiversidade do IEF, v.1, n.2, Belo Horizonte, Minas Gerais, 2008. 84pgs.

IVANUSKAS, M. N.; RODRIGUES, R. R. Florística e fitossociologia de floresta estacional decidual em Piracicaba, São Paulo, Brasil. Revista Brasileira de Botânica. V.23, n3, p.291-304, 2000.

JANZEN, D. H. Management of Habitat Fragments in a Tropical Dry Forest: Growth. Annales Missouri Botany Gardens, v. 75, p. 105-116, 1998. 
JÚNIOR, W. G. F.; SCHAEFER, C. E. G. R.; SILVA, A. F. Uma visão pedogeomorfológica sobre as formações florestais da mata atlântica. In: MARTINS, S. V. Ecologia de florestas tropicais do Brasil. $2^{a}$ Ed. UFV, Viçosa, Minas Gerais, 2012.

KALACSKA, M.; SANCHEZ-AZOFEIFA, G. A.; CALVO-ALVARADO, J. C.; QUESADA, M.; RIVARD, B.; JANZEN, D. H. Species composition, similarity and diversity in three successional stages of a seasonally dry tropical forest. Forest Ecology and Management, 200, pg.227-247, 2004.

KAMINO, L. H. Y.; OLIVEIRA-FILHO, A. T.; STEHMANN, J. R. Relações florísticas entre as fitofisionomias florestais da Cadeia do Espinhaço, Brasil. Rev. Megadiversidade, vol.4, nº 1-2, 2008.

KILCA, R. V.; SCHIAVINI, I.; ARAÚJO, G. M.; FELFILI, J. M. Diferenças estruturais e edáficas entre duas florestas estacionais no bioma cerrado. Revista Neotropical Biology and Conservation, v.4, n.3, p.150-163, 2009.

KÖNIG, F. G.; SCHUMACHER, M. V.; BRUN, E. J.; SELING, I. Avaliação da sazonalidade da produção de serrapilheira numa floresta estacional decidual no município de Santa Maria - RS. Revista Árvore, vol.26, n. 4, p.429-435, 2002.

LARCHER, W. Ecofisiologia vegetal. São Carlos, RiMa, 200.

LEPSCH, I. F. Formação e conservação dos solos. $2^{\text {a }}$ Ed. São Paulo, Ofinina de textos, 2010.

LIMA, V. V. F. DE.; VIEIRA, D. L. M.; SEVILHA, A. C.; SALOMÃO, A. N. Germinação de espécies arbóreas de floresta estacional decidual do vale do rio Paranã em Goiás após três tipos de armazenamento por até 15 meses. Revista Biota Neotropica, vol.8, nº3, 2008.

MADEIRA, B. G.; ESPIRITO-SANTO, M. M.; D'ANGELO-NETO, S.; NUNES, Y. R. F.; AZOFEIFA, G.A. S.; FERNANDES, G. W.; QUESADA, M. Changes in tree and liana communities along a successional gradient in a tropical dry forest in southeastern Brazil. Plant Ecology 201, 291-304. 2009.

MADEIRA, B. G.; ESPÍRITO-SANTO, M. M.;NETO, S.D; NUNES, Y. R. F.; AZOFEIFA, A. S.; FERNANDES, G. W.; QUESADA. M. Mudanças sucessionais nas comunidades arbóreas e de lianas em matas secas: entendendo o processo de regeneração natural.Revista MG Biota, Instituto Estadual de Florestas,vol.1, n.2, pg.28-36, 2008. (b)

MARAGON, L. C.; SOARES, J. J.; FELICIANO, A. L. P. Florística arbórea da mata da pedreira, município de Viçosa. Revista Árvore, v.27, n.2, p.207-215, 2003.

MINAS GERAIS - Lei 17353, de 17/01/2008 que dispõe sobre a alteração do uso do solo nas áreas de ocorrência de mata seca. Disponível em: http://consulta.almg.gov.br/consulte/legislacao/completa/completa. html?ano=2008\&num=17353\&tipo=LEI. Acesso em Jan $/ 2013$.

MINISTÉRIO DO MEIO AMBIENTE. Áreas prioritárias para conservação, uso sustentável e repartição de benefícios da biodiversidade brasileira: atualização. Portaria $\mathrm{MMA} \mathrm{n}^{\circ} 9$, de 23 de janeiro de 2007. 300p.

MURPHY. P. G. \& LUGO, A. E. Ecology of tropical dry forest. Annual review of ecologic and sistematics, v. 17, n.1, p. 67-88. 1986.

NASCIMENTO, R. T.; FELFILI. J.M; \& MEIRELES. M. A. Florística e estrutura da comunidade arbórea de um remanescente de floresta estacional decidual de encosta, Monte Alegre, GO, Brasil. Acta Botânica Brasilica, v.18, n.3, p.650-669. 2004.

NASCIMENTO, R. T.; FELFILI. J.M; FAGG, C. W. Estimativa da Abertura do dossel em duas florestas estacionais em afloramentos calcários no Brasil central com fotografias hemisféricas. Revista Árvore, Vol.31, 
n.1, Viçosa, 2007.

OLIVEIRA-FILHO, A. T.; SCOLFORO, J. R. S.; OLIVEIRA, A. D.; CARVALHO, L. M. T. (et al). Definição e delimitação de domínios e subdomínios das paisagens naturais do estado de Minas Gerais. In: SCOLFORO, J. R.; CARVALHO, L. M. T. Mapeamento e inventário da flora nativa e dos reflorestamentos de Minas Gerais. UFLA, Lavras, 2006.

PEDRALLI, G. Florestas secas sobre afloramentos de calcário em Minas Gerais: florística e fisionomia. Bios, v. 5 , n. 5 , p. $81-88,1997$.

PENNINGTON, R. T. PRADO, D. E. \& PENDRY, C. A. Neotropical Seasonally Dry Forests and Quaternary Vegetation Changes. Jornal of Biogeografhy, pg. 261-273. 2000.

PILÓ, L. B.; AULER, A. Geoespeleologia das cavernas em rocha ferrífera da região de Carajás, PA. In: Anais do $30^{\circ}$ Congresso Brasileiro de Espeleologia, 2009.

POWERS, J. S.; BECKNELL, J. M.; IRVING, J.; PÉREZ-AVILES, D. Diversity and structure of regenerating tropical dry forest in Costa Rica: geographic patterns and environmental drivers. Forest Ecology and Management, 258, pg.959-970, 2009.

PRADO. D. E \& GIBBS. P.E. Patterns of Species distribitions in the dry seasonal south America. Annal of the Missouri Botanical Garden, v. 80, n.4, p. 902-927. 1993.

QUESADA, M. et al. Succession and management of tropical dry forest in the Americas: review and new perspectives. Forest Ecology and Management, 258, pg.1014-1024, 2009.

RIBEIRO, J. F.; WALTER, B. M. T. Fitofisionomias do bioma cerrado. In: SANO, S. M.; ALMEIDA, S. P.; RIBEIRO, J. S. (Ed.) Cerrado: ambiente e flora. Planaltina, Embrapa Cerrados, 2008. Cap.5.

RICKLEFS, R. Biodiversidade. In: A economia da natureza. 5a Ed., Guanabara Koogan. 2001.

RIZZINI, C. T. Tratado de fitogeografia do Brasil: aspectos ecológicos, sociológicos e florísticos. $2 .{ }^{a}$ Ed. Âmbito Cultural Edições Ltda, 1997.

RODRIGUES, B. D.; RIBEIRO, C. M. Aplicação da teoria dos refúgios ecológicos sobre a flora rupestre de Lagoa Santa, Minas Gerais, Brasil. 12 ${ }^{\circ}$ Encontro de Geógrafos da América Latina, Montevidéo, Uruguai, 2009.

SALIS. S. M. et al; Fitofisiologia de remanescentes de florestas estacionais deciduais em Corumbá, Mato Grosso do Sul, Brasil. Revista Brasileira de Botânica. V.27, n4, p 71 - 684. 2004.

SÁNCHEZ-AZOFEIRA, G. A.; KALACSKA, M.; ESPÍRITO-SANTO, M. M.; FERNANDES, G. W.; SCHNITZER, S. Tropical dry Forest succession and the contribution of lianas to Wood area index (WAI). Forest Ecology and Management, 258, 941-948, 2009.

SÁNCHEZ-AZOFEIFA G. A, et al., Research prioities for neotropical dry forests. Biotropica, v37, n. 4, 2005.

SANTOS, F. A. M.; MARTINS, F. R.; TAMASHIRO, J. Y. Variação temporal das interações bióticas na comunidade arbóreo-arbustiva em um fragmento de cerrado. Relatórios da disciplina Ecologia de Campo II. 2006. Programa de Pós Graduação em Ecologia e Biologia Vegetal. Unicamp, disponível em: http://www2. ib.unicamp.br/profs/fsantos/ecocampo/ne211/2006/R2-NE211-A.pdf Acesso: Outubro de 2012.

SANTOS, R. F.; CARLESSO, R. Déficit hídrico e os processos morfológico e fisiológico das plantas. Revista Brasileira de Engenharia Agrícola e Ambiental, v.2, n.3, p.287-294, Campina Grande, 2008. 
SCARIOT, A. \& SEVILHA, A. C. Biodiversidade, estrutura e conservação de florestas estacionais deciduais no Cerrado. In: Cerrado: ecologia, biodiversidade e conservação. Brasília. Ministério do Meio Ambiente, 2005.

SEVILHA, A. C.; SCARIOT, A.; NORONHA, S. Estado atual da representatividade de unidades de conservação em florestas estacionais deciduais no Brasil. In:55 Congresso Nacional de Botânica e Simpósio Unidades de Conservação nos Biomas Brasileiros, 2004. 60pgs.

SHINZATO, E. O carste da Área de Proteção Ambiental de Lagoa Santa (MG) e sua influência na formação dos solos. Dissertação de Mestrado da Universidade Estadual do Norte Fluminense, Campos dos Goytacazes, Rio de Janeiro, 1998.

SILVA, I. C. Caracterização da vegetação arbórea em área de contato Savana/Floresta Estacional. Dissertação de Mestrado, Universidade de Brasília, Pós Graduação em Ciências Florestais, 2011.

SILVA, L. A.; SCARIOT, A. Composição florística e estrutura da comunidade arbórea em uma floresta estacional decidual em afloramento calcário (Fazenda São José, São Domingos, GO, Bacia do Rio Paranã). Revista Acta Botânica Bras. N.17, vol2, p.305-313, 2003.

SILVA, M. L. A Dinâmica de Expansão e Retração de Cerrados e Caatingas no período Quaternário: uma Análise Segundo a Perspectiva da Teoria dos Redutos Refúgios e Florestais. Revista Brasileira de Geografia Física, v. 4, n. 1, 2011.

N.17, vol2, p.305-313, 2003.

SILVA, M. C. N. A; RODAL, M. J. N. Padrões das síndromes de dispersão de plantas em áreas com diferentes graus de pluviosidade. Acta Botânica Bras. Vol.23, n.4, 2009. Pg.1040-1047.

SKORUPA, A. L. A.; GUILHERME, L. R. G.; CURI, N.; SILVA, C. P. C.; SCOLFORO, J. R. S; MARQUES, J. J. G. S. M. Propriedades de solos sob vegetação nativa em Minas Gerais: distribuição por fitofisionomia, hidrografia e variabilidade espacial. Revista Brasileira de Ciência do Solo, vol.36, n.1, pg.11-22, Viçosa, 2012.

STONER, K. E.; SÁNCHEZ-AZOFEIFA, G. A. Ecology and regeneration of tropical dry Forest in the Americas: implications for management. Forest Ecology and management, vol. 258, pg. 903-906, 2009.

TABARELLI, M.; MELO, M. D. D. V. C.; LIRA, O. C. Os estados da mata atlântica. In: CAMPANILI, M.; PROCHNOW (orgs). Mata Atlântica: uma rede pela floresta. Rede de Ongs da Mata Atlântica, Brasília, 2006. Pg37-165.

TROPI-DRY. Esclarecimentos sobre a situação ecológica e sócio-econômica das Matas Secas norte mineiras. Nota técnica da Rede Colaborativa de Pesquisas Tropi-Dry. Publicação de 2010. Disponível em: http://tropidry.eas.ualberta.ca/pdf/Papers/Em defesa da mata seca-junho 2010-mapas-2-2.pdf Acesso em Jan. 2012.

VIEIRA, D. L. M. Regeneração natural de florestas secas: implicações para restauração. Tese de doutorado do Instituto de Biologia da Universidade de Brasília, 2006.

WERNECK, M.S; FRANCESCHINELLI, E.V; TAMEIRÃO-NETO, E. Mudanças na florística e estrutura de uma floresta decídua durante um período de quatro anos (1994-1998), na região do triângulo mineiro, MG. Revista Brasileira de Botânica, v.23, n. 4, p. 401-413, 2000.

ZHOURI, A.; BARBOSA, R. S.; ANAYA, F. C.; ARAÚJO, E. C.; SANTOS, F. D.; SAMPAIO, C. Processos socioambientais nas Matas Secas do norte de Minas Gerais: políticas de conservação e os povos do lugar. Rev. MG Biota, v.1, n.2, 2008. 